\title{
Organic cotton - A new perspective
}

\author{
Sharmila Nagraj ${ }^{1}$, Sharada Devi ${ }^{2}$ \\ I'Apparel and Textiles Department, College of Home Science, Acharya N G Ranga Agricultural University, \\ India) \\ ${ }^{2}$ (Apparel and Textiles Department, College of Home Science, Acharya N G Ranga Agricultural University,
} India)

\begin{abstract}
The organic cotton textiles are being used widely all around the globe. With the ban of lot of dye varieties and processes natural dyes and age old dyeing processes are coming back. In every part of the globe there were processes around textile spinning, dyeing, weaving and finishing which were followed meticulously with consciousness. In the last few decades due to massive technological advancement and in making everything in 100s and 1000s of pieces every country around the globe has lost lot of its unique treasures which could not stand up to the metal mechanics. Today lots of communities, cities and countries are in the mode of co-creating the old realms. Slow processes are coming back in textiles and apparel. Products with consciousness, environmental tags, and sustainable designs are being made. Water, yarn and fabrics are tested with poly interference photography, GDV and EIS, pre and post detoxification process. Significant changes were observed in the values in organic cotton, naturally dyed materials, after the detoxification process of water, yarn and fabric. Methods used for detoxification had a positive impact on the fabric which will be passed on to the wearer for improvements in long term physical, physiological and emotional state.
\end{abstract}

Keywords: Consciousness, Detoxification, Natural dyes, Organic cotton, Energy fields

\section{Introduction}

India is the most powerful nation today with its diversity and knowledge in varied fields. Its art and craft is known all over the globe for its history, age old techniques, processes, craftsmanship and fineness. The land of Bharath has intrigued experts from all walks of life be in the nano technology, space technology or grass root technology. The world over is spending time to understand what we do, how we do and why we do things the way we do things. As an emerging powerful economy India is a happening research ground.

The world's greatest civilizations have been exposed to the cycle of human intelligence and experiences. What was the perfect solution for an era was questioned, debated and scrutinized in another era of that country and the world. There remained a balance between the fast and the slow, high technology to low technology around life.

Every country of the world had its own system of consciousness to keep its flora and fauna, its rivers and mountains, its human and animal population in perfect tuning for a harmonious living. With the advent of technology, information and super human intelligence came the use, over use and abuse of certain resources there by creating depletions and piling up of residues.

The world stuck in fast forward and obsessed with speed, with doing everything faster, with cramming more and more into less and less time. Every moment of the day feels like a race against the clock. Carrie Fisher (2004) says "These days even instant gratification takes too long." We try to make things better by speeding them up, so we used to dial; now we speed dial. We used to read; now we speed read. We used to walk; now we speed walk. And even things that are by their very nature slow we try and speed them up too like speed yoga (Carl Honoré, 2004).

In the process of speed, technology and manufacturing more and more for cheaper products and sourcing all across the globe the process has lost the conscious connections of the artisans, weavers and tailors. Consumers are picking up products which are more convenient easy to handle and wear, cheaper as they are mass manufactured and ending up with goods with no human emotion and soul to it. Handmade textiles and garments are losing ground for lack of speed, technology, mass production, uniformity, and price.

The art of natural dyeing has come full circle - essentially due to the bans being imposed on synthetic dyes by European Governments. As a result of health risks from synthetic dyes, there is a new interest in natural dyes. Once again the ancient textiles and dyers of South Asia are coming back to haunt the modern day textiles. This is evident from the discovery of a dyer's workshop at Mohenjodaro. Indigoferra Tinctoria, the most fabled, ancient plant for the indigo dye also grew in abundance on the banks of River Indus.

The waters were clear, raw materials pure, land natural and the fiber which grew was as sweet as candy. Today with the bombardment of chemicals and GMO $\mathrm{s}$ in all spheres of existence human beings are craving for something pure and natural which can be used with confidence even without looking at the label or tag. 
This research was under taken to bring back the goodness of organic cotton(GoTs), natural dyes, hand loom, textile design (Colour Horoscope Weaving) and custom clothing. The objective was to show consciousness in all the processes in the supply chain can imbibe positive energy. To prove that slow processes not only make products with conscious core but also influence the health parameters of the wearer. Twenty men and twenty women subjects were chosen for this study.

\subsection{Detoxification}

\section{Methods}

The process of cleansing is called detoxification. In this study music was used in detoxification of water and yarn. Music (Strotras) from the Vedas was used in a particular sequence for every procedure. Lalitha Sahasranamam, Totakashtakam, Aditya Hrydayam and Kanadhara Strotram were played on the audio for detoxification.

The weavers themselves believe that the whole weaving process is a ritual than a mere mechanical work. Women were not allowed in the dyeing and weaving section if they are in their menstrual cycles. It is believed that certain natural colours don't ferment well especially indigo.

\subsubsection{Yarn}

The yarn came in bundles of 4.6-4.8 kgs. These were stored in a small storage under plastic sheets. The yarn bundles to be dyed where arranged in a pile and detox music was played for one hour before it was dipped in the water which was already detoxed.

The dried yarn was kept separately under cotton cloth covers after detoxification and music was played again to repeat the detoxification procedure before dyeing process.

\subsubsection{Fabric}

The fabric was woven on a handloom in a unique textile design called the Colour Horoscope Weaving which is a copyright design of Ms Bonnie Tarses a textile designer from Rhode Island School of Design, USA. This created horizontal stripes of all colours of colour wheel in different numbers depending on the horoscope. For comparison a fabric was woven in bands of 120 yarns each of all the 12 colours of the colour wheel to create a fabric with horizontal equal width stripes.

\section{2 $\quad$ Energy Fields}

\subsubsection{PIP Poly contrast interference Photography}

Polycontrast Interference Photography (PIP) is an energy field video imaging process. This is new experimental technology reveals patterns of light that are not visible to the naked eye. PIP, in and of itself, is not merely a device or product. It is a method, or process, which requires copyrighted materials, and is driven by an intricate system of calculations and formulas. In other words, PIP is really intellectual property, integrated into software that performs a technical process to generate images. (Harry Oldfield 1986). The equipment needs standard setting up procedures which is prescribed.

Even though many millions of different colours that can be detected by the human eye. However only 256 colours are possible on the computer screen which is sufficient for analytical purposes in PIP. Colour is vital as it reveals "life-force". The colour spectrum starts with white and includes tones of all colours that follow.

The interpretation of the PIP pictures was carried out by the customized software and the colours (Appendix $\mathrm{O}$ ) which were analyzed mainly are explained below:

- Blue: Blue is a cooling colour. Blue colour in the bio field indicated soothing and healing energy process.

- Green: Green colour was associated with balance.

- Pink /Violet: It was the highest and fastest vibrating colour showing spiritual, soothing spectrum in relaxation and in healthy states of spirituality and meditation.

- Yellow: Yellow was found in the bio field indicated vitality and general wellness.

- Orange: Orange in a bio field indicates hyperactivity in a negative scenario orange like red was related to lower energy.

- Red: Where there was an imbalance of energy flow it appeared as thickened red lines or congested pools.

\subsubsection{Pre testing of naturally dyed cotton yarn}

The yarn was tested pre and post detox. The yarn skein about 50 grams was placed on a stool covered with white cloth.

- Cotton yarn regular was placed in the center space on the stool and a PIP shot is taken.

- Normal $100 \%$ organic cotton yarn skein is placed at the center of the stool and a shot is taken with the camera. 
- Normal $100 \%$ organic cotton yarn skein which was detoxed by the standard procedure is placed at the center of the stool and a shot is taken with the camera.

- $100 \%$ naturally dyed organic cotton yarn which was detoxed by the standard procedure is placed and the above procedure is followed to get the picture of the yarn.

\subsubsection{Post testing of organic cotton naturally dyed horoscope fabric.}

- The fabric is woven in 12 colours of the colour wheel was tested in the same procedure.

- The colour horoscope fabric was also tested in the standard PIP procedure and results are compared with the above mentioned fabric for the energy levels.

\subsubsection{Gas Discharge Visualization - Electro Photon Imaging (GDV -EPI)}

A wide range of instruments makes it possible to use GDV techniques in various fields of human activities - medicine, professional sports, fitness, spa, areas of psychology, psycho-physiology, and also in basic and applied research.

GDV programs were formed as a sequence of pages leading the user step by step along the accepted scheme of GDV image analysis. This made the study process maximally convenient and clear. The programs for diagnostics (sector analysis) work with lists of subjects that enable the user to store not only personal information (name, gender, age, etc.) but also comments about GDV capturing.

The energy field created a model of human energy field on the basis of the topic map correlation between the glow of separate sectors of human fingers and his/her biological systems and organs. The output given was an image around human contour; numeric presentation of data in tables and diagrams, calculation of energy field parameters: area, entropy and fractality.

A pre-analysis (BF) was done which will be used as a standard against which the post analysis (AF) (after wearing the organic clothing) will be compared. This makes three energy projections-fronts, left and right. This provides means for a detailed analysis of the state of the whole organism.

The following parameters were calculated and analyzed in Table no:

- Area: This parameter describes the size of the bio-energy field, measured in the number of pixels. This parameter is calculated for all three projections separately.

- Entropy: Reflects the level of functional ability of the organism in the process of exchange of matter, information and energy with the environment.

- Fractality: The parameter Fractality describes the irregularity if the outer contour of the bio- energy field. It is a measure of the uneven distribution of the energy field and the different levels of the body.

\subsubsection{Process of data collection}

GDV machine takes finger impression of all the ten fingers. The subject stood straight with no foot wear and placed the thumb on the glass plate of the GDV camera. Index, middle, ring and small finger impressions were taken on that order one after the other for the right and the left hands. Precautions were taken to remove all the metal ornaments on the body. Electronic devices like cell phones etc are kept away as these interfere with energy fields.

The finger impression snap shots were taken with filter (on glass) and without filter which give physical and emotional state of the person respectively. Once the data was collected it was saved with the subject's unique code to maintain secrecy of information. It was the processed and harnessed to get data in the form of numerical charts, graphs, pictures and integral diagrams.

\subsection{Yarn:}

\section{Results}

The energy field of the organic yarn was tested before and after detoxification and dying with natural dyes.

The analyzed data is captured in the table below:

TABEL1: Energy fields in Organic Cotton yarn

\begin{tabular}{|l|r|r|r|r|}
\hline & $\begin{array}{c}\text { Negative } \\
\text { (Orange } \\
\text { Pixels) }\end{array}$ & $\begin{array}{c}\text { Soothing } \\
\text { (Blue } \\
\text { Pixels) }\end{array}$ & $\begin{array}{c}\text { Spiritual } \\
\text { (Pink Pixels) }\end{array}$ & $\begin{array}{c}\text { Balance } \\
\text { (Green } \\
\text { Pixels) }\end{array}$ \\
\hline Organic Cotton Yarn & 21049 & 14860 & 39547 & 30874 \\
\hline Organic Cotton Yarn Charged & 14111 & 9653 & 23546 & 43284 \\
\hline Percentage Gain / Loss (+/ - & $\mathbf{- 3 2 . 9 6}$ & $\mathbf{- 3 5 . 0 4}$ & $\mathbf{- 4 0 . 4 6}$ & $\mathbf{4 0 . 2 0}$ \\
\hline
\end{tabular}




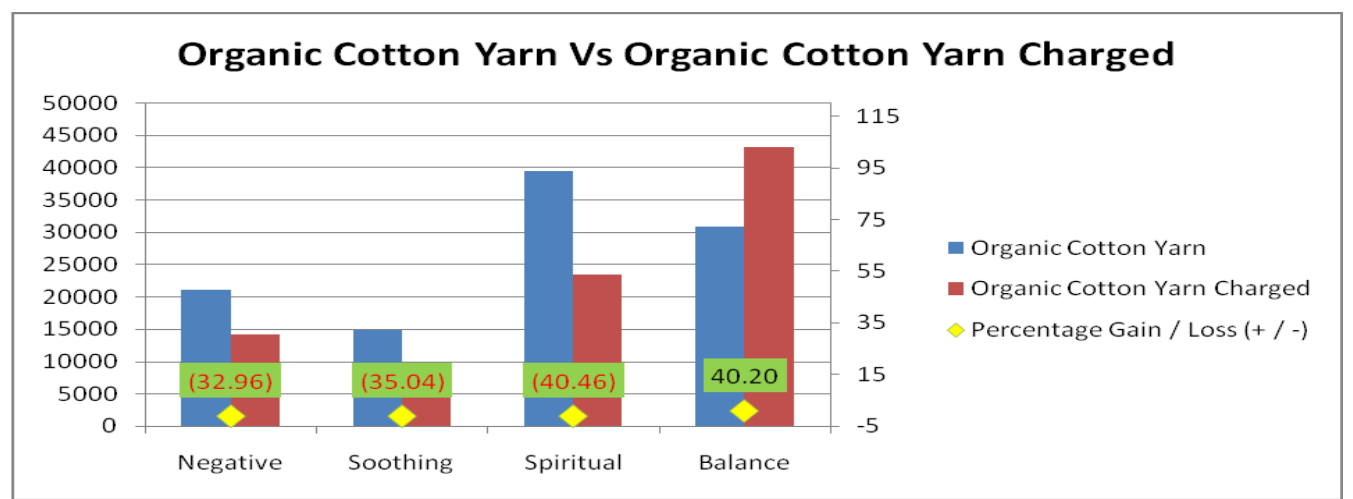

Figure 1: Energy fields in Organic Cotton yarn.

As read from the above table 1 and Fig 1 the organic cotton yarn had recorded negative energy of 21049 Pixels which was reduced by $1 / 3^{\text {rd }}$ due to detoxification. The balancing energy had increased to a greater extent of 40.20 per cent. The remarkable energy reduction was observed which can be attributed to the transport of materials form Hyderabad to Pune for testing and also due to handling by people. Though the soothing and spiritual energies have reduced it could be enhanced by detoxification of waters and yarn.

TABLE 2: Energy fields in Organic Cotton Yarn and Natural Dyed

\begin{tabular}{|l|r|r|r|r|}
\hline & $\begin{array}{c}\text { Negative } \\
\text { (Orange Pixels) }\end{array}$ & $\begin{array}{c}\text { Soothing } \\
\text { (Blue } \\
\text { Pixels) }\end{array}$ & $\begin{array}{c}\text { Spiritual } \\
\text { (Pink } \\
\text { Pixels) }\end{array}$ & $\begin{array}{c}\text { Balance } \\
\text { (Green } \\
\text { Pixels) }\end{array}$ \\
\hline Organic Cotton Yarn & 21049 & 14860 & 39547 & 30874 \\
\hline Organic Cotton Yarn Natural Dyed & 17303 & 16712 & 25271 & 39657 \\
\hline Percentage Gain / Loss (+/ -) & $\mathbf{- 1 7 . 8 0}$ & $\mathbf{1 2 . 4 6}$ & $\mathbf{- 3 6 . 1 0}$ & $\mathbf{2 8 . 4 5}$ \\
\hline
\end{tabular}

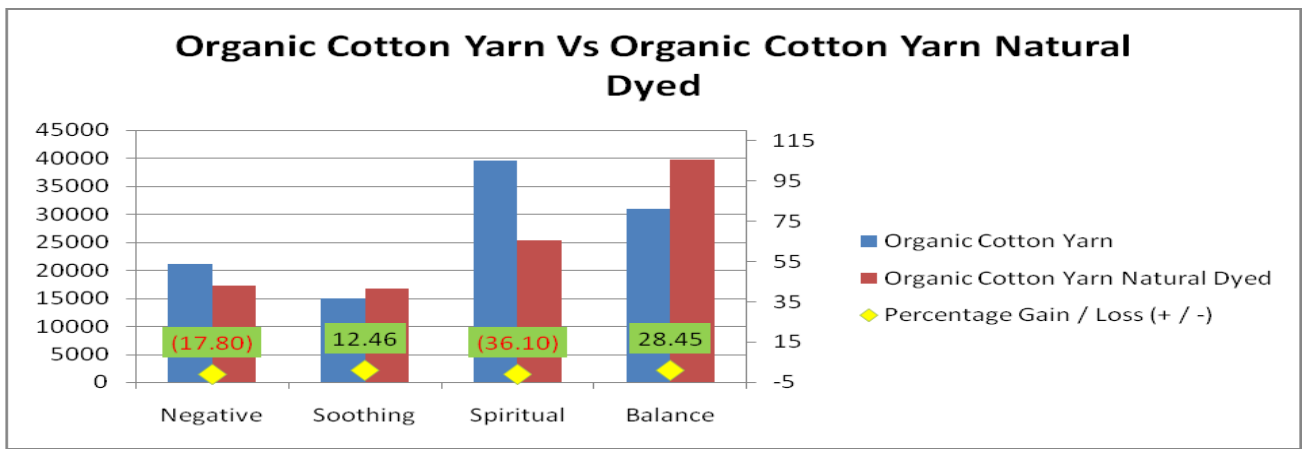

Figure 2: Energy fields in Organic Cotton Yarn and Natural Dyed.

An attempt was made to see the effect of natural dye on organic cotton yarn without detoxification. A significant reduction in negative energy was found in natural dyed organic cotton yarn proving that the natural colours inherently have good energy imbibing elements. As per the data the dyeing process had reduced the negative energy by 17.80 per cent. The balancing energy had increased by 28.45 per cent. There are so many factors in today's world which affect the material and process due to handling, pollution, adulteration, improper storage etc. Though the spiritual energies had reduced, it could be enhanced by detoxification of waters, yarn, and dye used.

TABLE 3: Energy fields in Dyed Organic Cotton yarn

\begin{tabular}{|l|r|r|r|r|}
\hline & $\begin{array}{c}\text { Negative } \\
\text { (Orange } \\
\text { Pixels) }\end{array}$ & $\begin{array}{c}\text { Soothing } \\
\text { (Blue } \\
\text { Pixels) }\end{array}$ & $\begin{array}{c}\text { Spiritual } \\
\text { (Pink } \\
\text { Pixels) }\end{array}$ & $\begin{array}{c}\text { Balance } \\
\text { (Green } \\
\text { Pixels) }\end{array}$ \\
\hline Organic Cotton Yarn Natural Dyed & 17303 & 16712 & 25271 & 39657 \\
\hline Organic Cotton Yarn Natural Dyed + Charged & 16360 & 27364 & 28798 & 49767 \\
\hline Percentage Gain / Loss (+ / -) & $\mathbf{- 5 . 4 5}$ & $\mathbf{6 3 . 7 4}$ & $\mathbf{1 3 . 9 6}$ & $\mathbf{2 5 . 4 9}$ \\
\hline
\end{tabular}




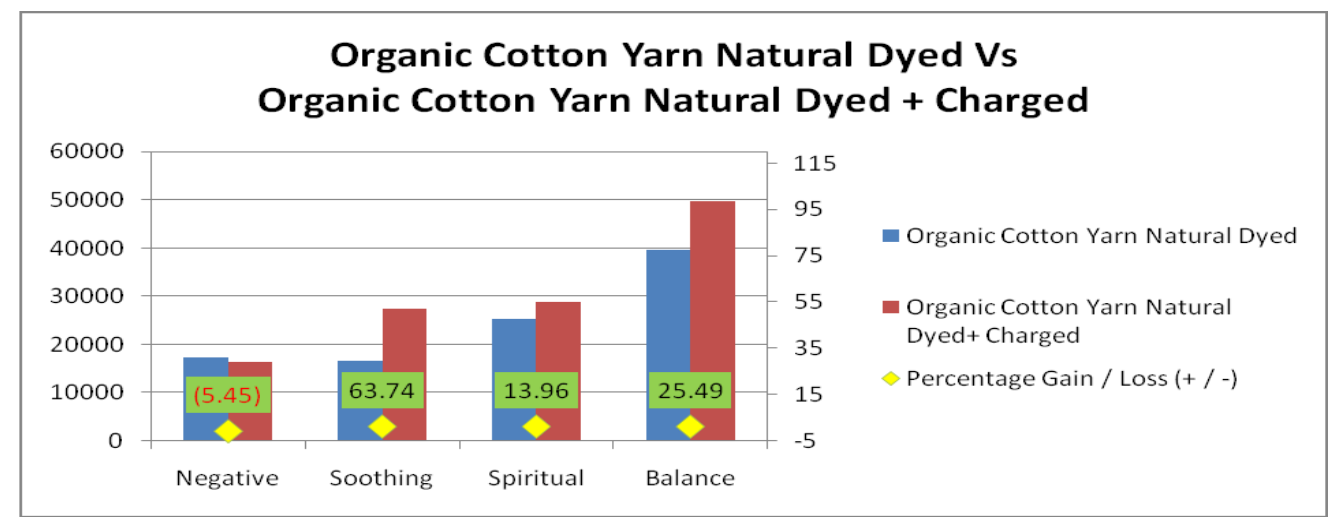

Figure 3: Energy fields in Dyed Organic Cotton yarn.

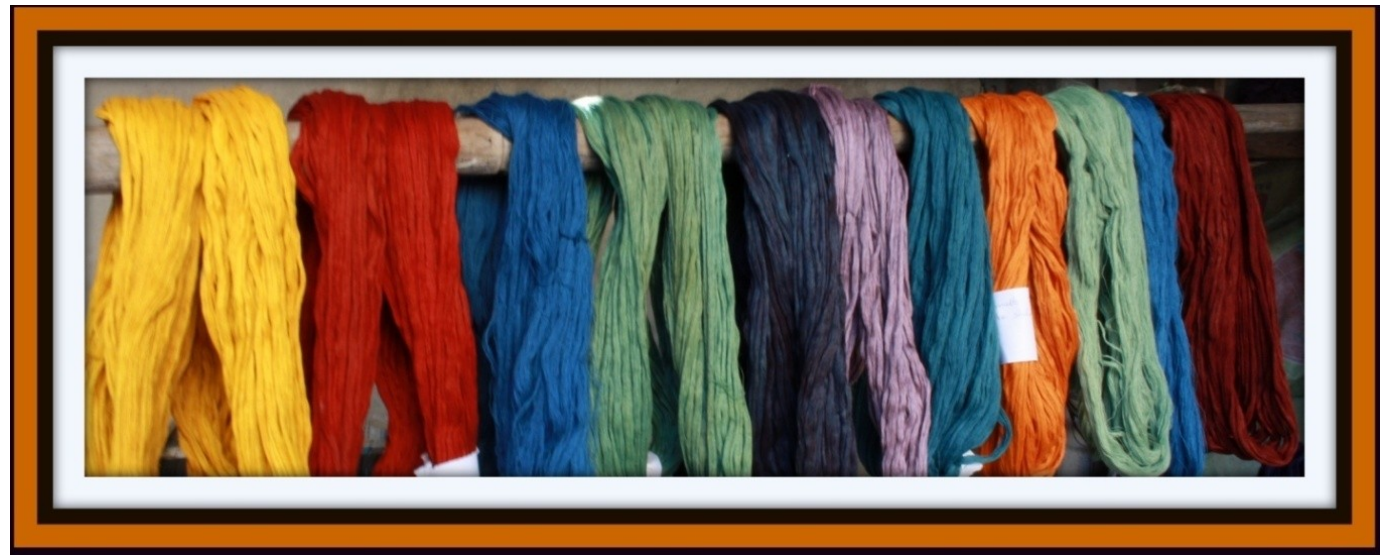

Figure 4:Naturally Dyed 100\% Organic Cotton.

Table 3and Fig 3 explains that the organic cotton yarn natural dyed showed negative energy which was reduced by detoxifying. As per the data the natural dyeing and detoxification process had reduced the negative energy by 5.45 per cent. The soothing, spiritual and balancing energy were increased by 63.74 per cent, 13.96 per cent, and 25.49 per cent respectively.

From the above analysis and data interpretation it is proved that the detoxification methods significantly enhanced the energy fields in the materials. Using natural dyes for dyeing regular or organic cotton showed significant positive results in the energy fields. The organic yarns after detoxification had been woven on handloom in a unique textile design technique called the colour horoscope weaving.

The resultant fabrics were tested and compared with a fabric woven using all the 12 colours of the colour wheel.

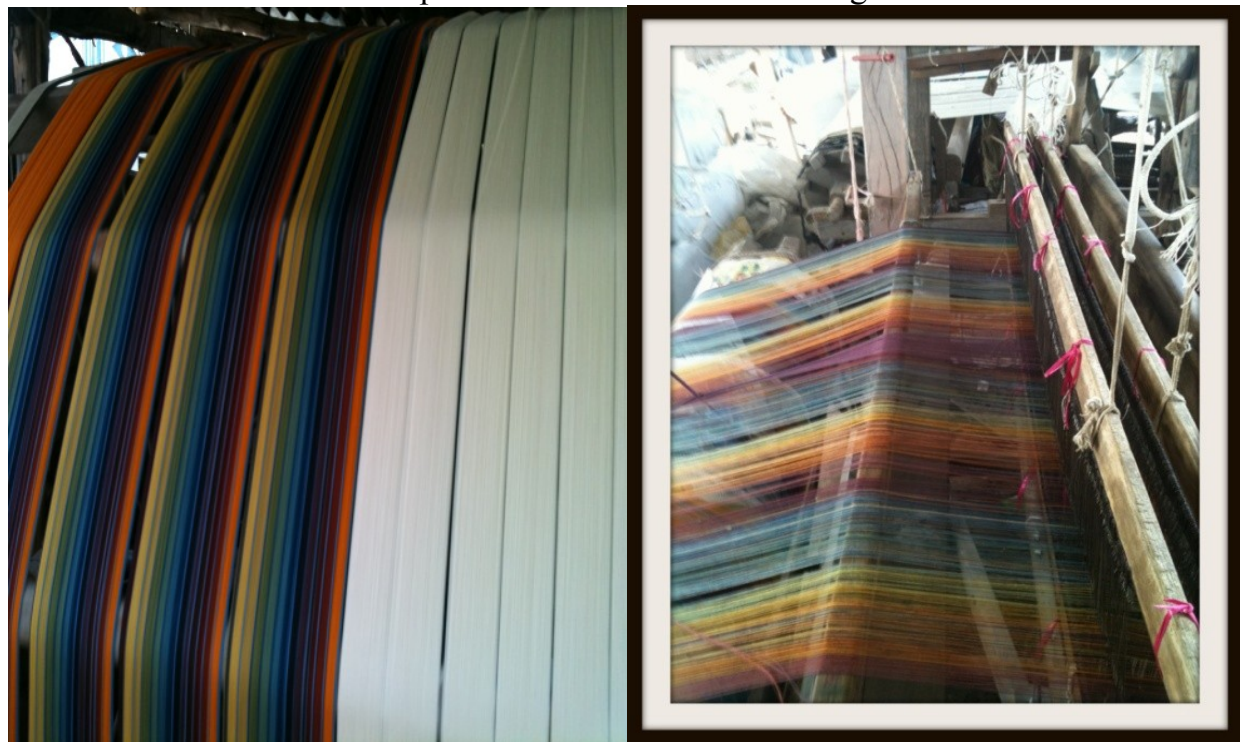

Figure 5: Colour Wheel Fabric (left) - Colour Horoscope Weaving (right) 
The analyzed data is captured in the table below:

TABLE 4: Energy fields in Woven fabrics

\begin{tabular}{|l|r|r|r|r|}
\hline & $\begin{array}{c}\text { Negative } \\
\text { (Orange } \\
\text { Pixels) }\end{array}$ & $\begin{array}{c}\text { Soothing } \\
\text { (Blue } \\
\text { Pixels) }\end{array}$ & $\begin{array}{c}\text { Spiritual } \\
\text { (Pink } \\
\text { Pixels) }\end{array}$ & $\begin{array}{c}\text { Balance } \\
\text { (Green } \\
\text { Pixels) }\end{array}$ \\
\hline Colour Wheel Fabric & 15645 & 8195 & 31817 & 39767 \\
\hline Average Of all Horoscope Fabrics & 13462.33 & 19697.17 & 27001.5 & 42822 \\
\hline Percentage Gain / Loss (+/ -) & $\mathbf{- 1 3 . 9 5}$ & $\mathbf{1 4 0 . 3 6}$ & $\mathbf{- 1 5 . 1 4}$ & $\mathbf{7 . 6 8}$ \\
\hline
\end{tabular}

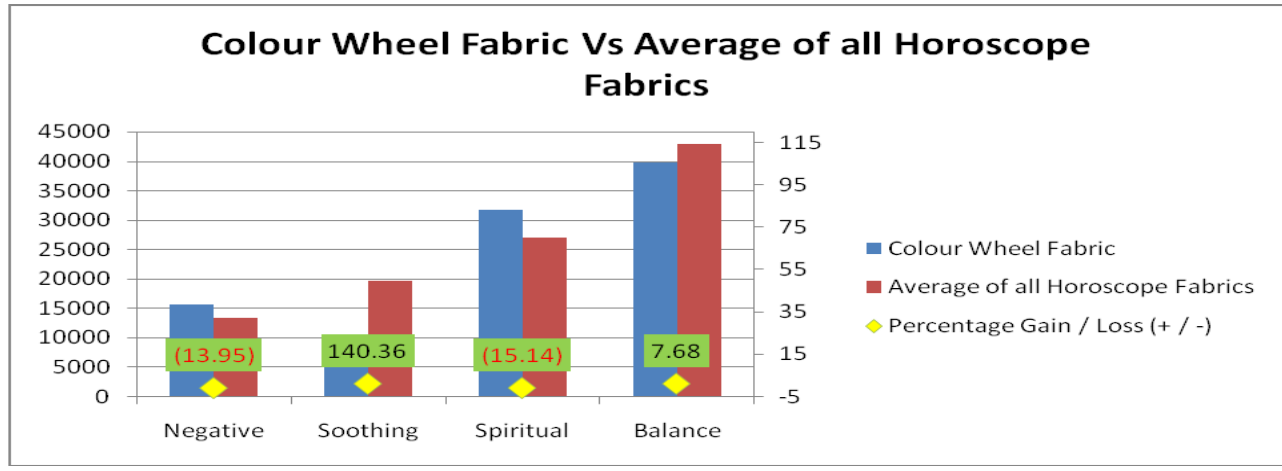

Figure 6. Energy fields in Woven fabrics.

Table 4. and Fig 6.explains that the organic cotton fabric woven in colour wheel pattern had more negative energy compared to the fabrics which were woven in horoscope design. The negative energy was reduced by 13.95 per cent. The colour horoscope weaving showed a very huge significant increase 140.36 per cent in soothing energy compared to the colour wheel pattern. The balance was enhanced by 7.68 per cent. The spiritual energy was reduced by 15.14 per cent which might be due to the handling which could be enhanced by the detoxification method.

The present life style brings in lot of stress in everyday living. The horoscope weaving has clearly shown that it can bring soothing energy which in turn could influence various factors such as de-stressing, bring calmness and also enhance concentration and focus in one's life.

\subsection{Gas discharge visualization}

The gas discharge visualization (GDV) software after capturing the finger readings facilitated analysis and documentation of the bio-energy field based in the calculation of special energy field parameters and their correlation to organs and organ systems of the subject. The reading without filter and with filter gave emotional and physical state of the subject respectively.

The possibilities of providing holistic medical screening through measurement of bioenergy fields which have both biophysical and biophysic bearings (Lee, 2005)

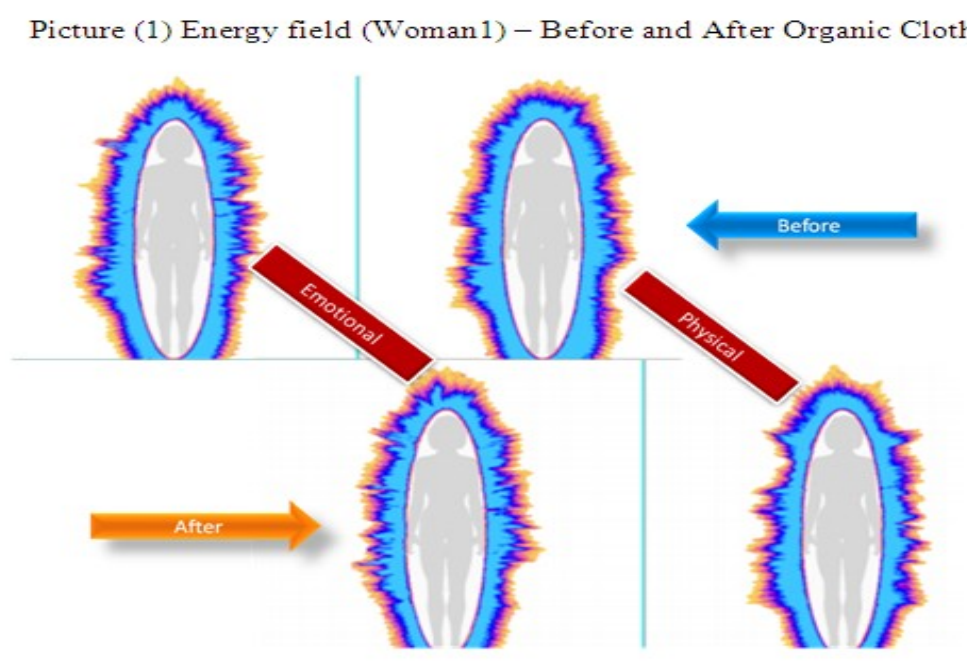

Figure 7: Energy Fields Woman 1 -Before and after wearing custom organic clothing 


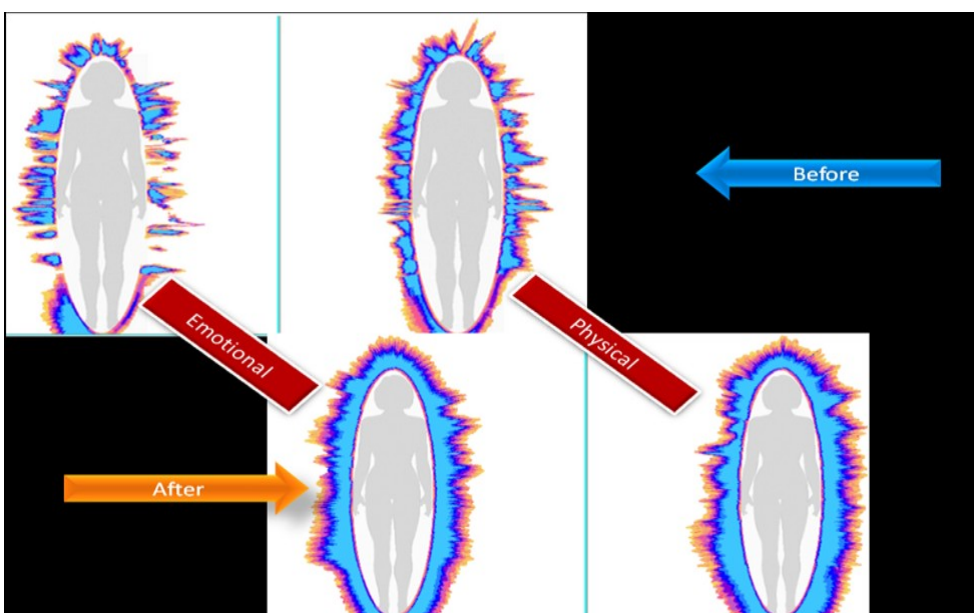

Figure 8: Energy Fields Woman 2 -Before and after wearing custom organic clothing

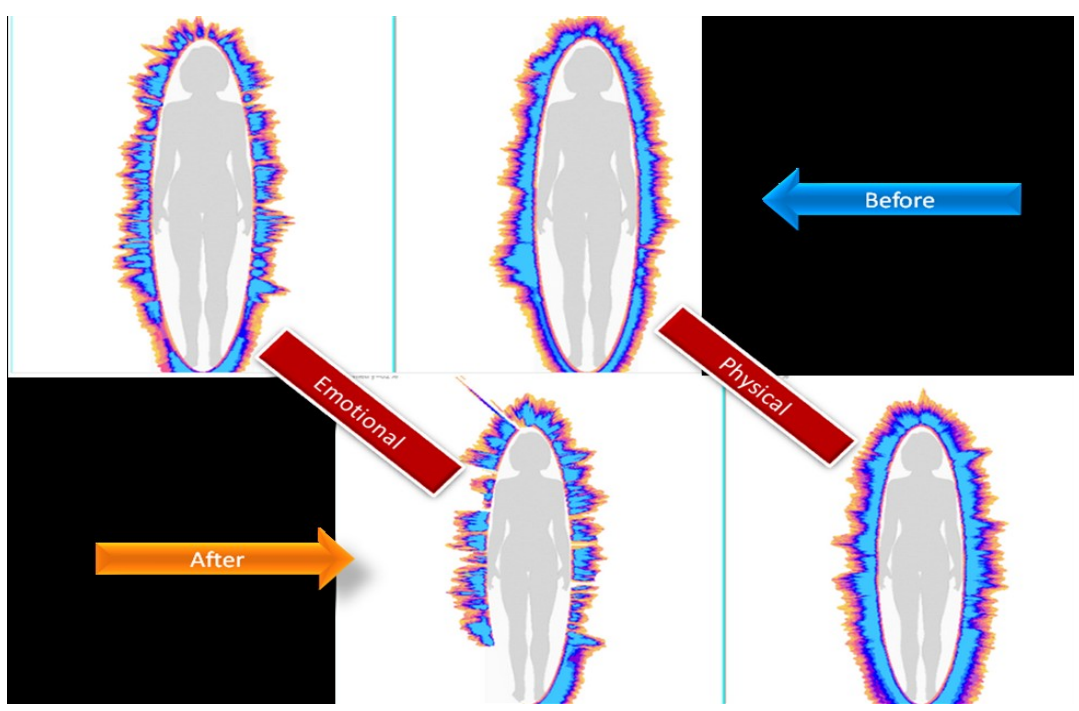

Figure 9: Energy Fields Woman 3 -Before and after wearing custom organic clothing

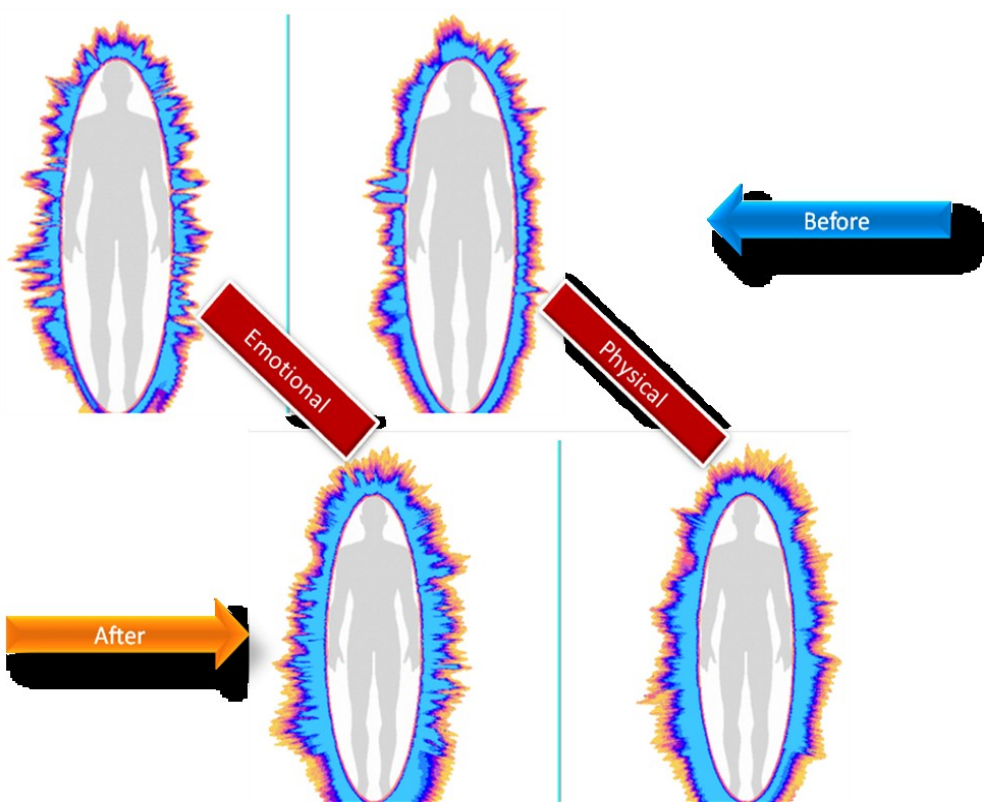

Figure 10: Energy Fields Man 1 -Before and after wearing custom organic clothing 


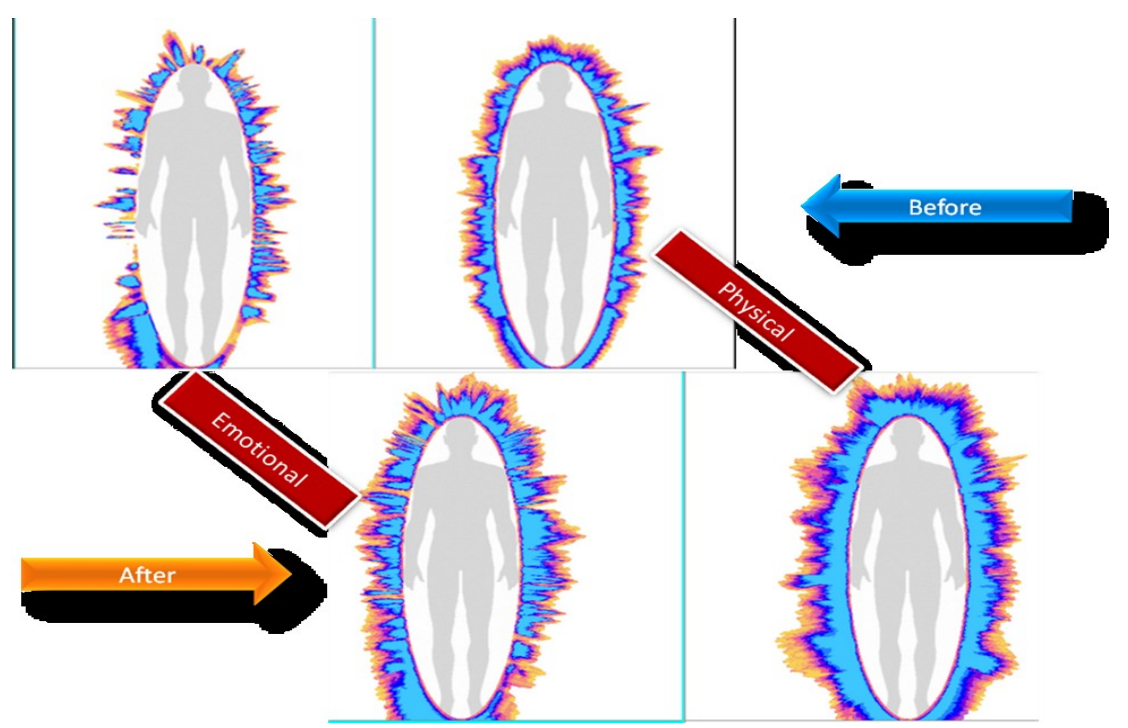

Figure 11: Energy Fields Man 2-Before and after wearing custom organic clothing

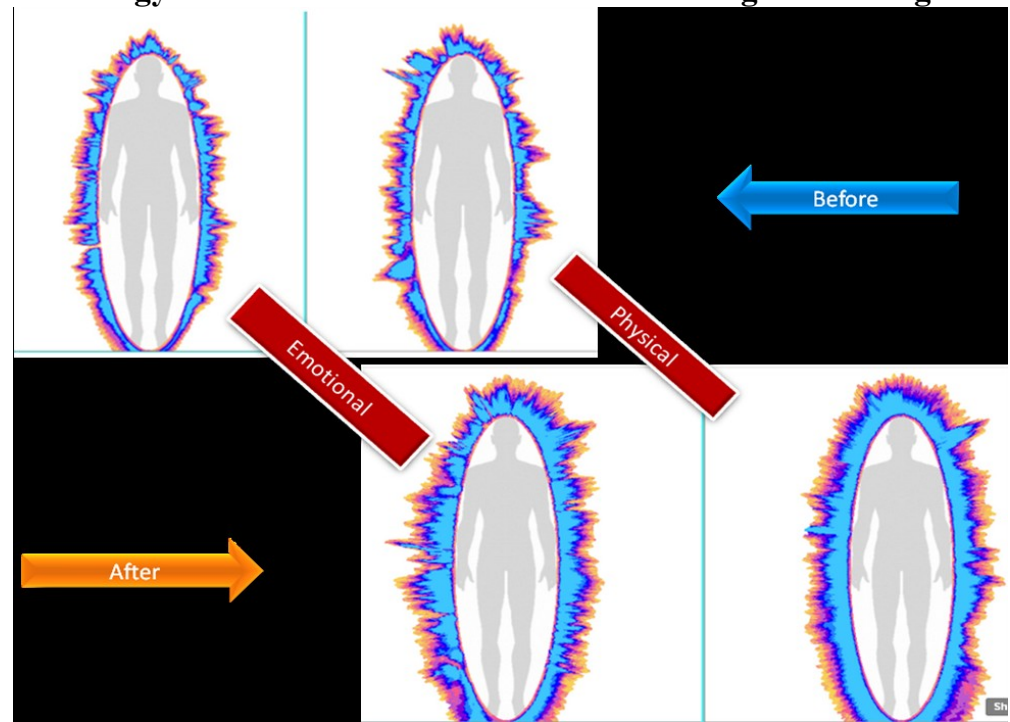

Figure 12: Energy Fields Man 3 -Before and after wearing custom organic clothing

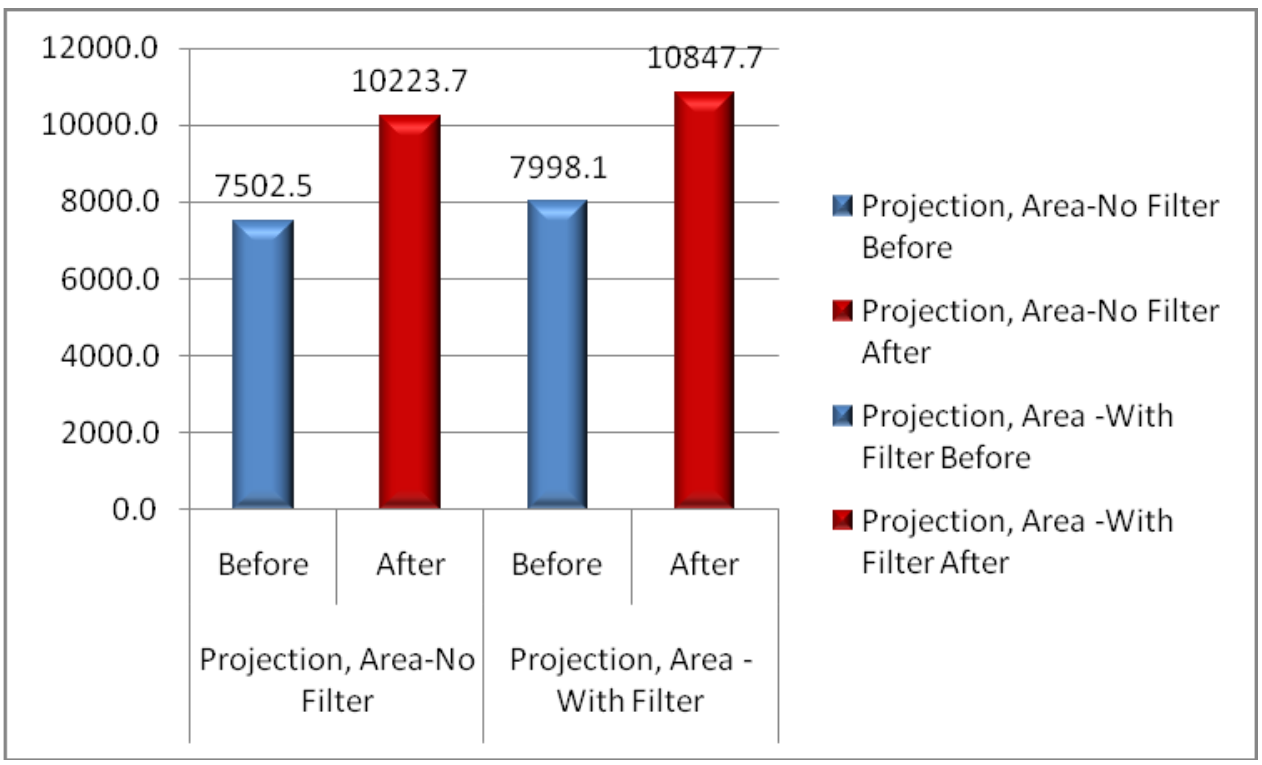

Figure 13: Total Average increase in Projection Area (No-Filter and With-Filter). 
Figs 7- 12 show the significant differences in 3 women and 3 men. Fig 13 shows the average increase and decrease of the entire ( 40 subjects ) projection area which clearly depicts that the emotional (no filter) and physical state (with filter) of the subject has been greatly influenced by the organic cotton naturally dyed custom clothing. The increase in the readings post organic clothing showed very significant increase in the size of the bio energy field by 36.3 per cent without filter and 35.6 per cent with filter, which indicates the state of well being of the subjects.

The bio-electrographic method understands the analysis of electro-photonic emission of human fingertips in a high intensity electromagnetic field and has significant dependence on human bio-responses to a disease, drug treatment or environment (Cohly et al, 2009)

\section{Conclusions:}

The process of making organic cotton yarn and natural dyes is a slow process which results in a fiber and a dye which will survive hundreds of years. (The excavations of Mohenjodaro and Harappa proved the age of linen/cotton and indigo dyes). The Indian sub continent which nurtures various traditions and cultures which in turn have had their unique systems in making and using clothing in and around their families and community. Each of these processes and methods had ritual and steps which were followed astringently.

Now with few weavers left to do the craft it has remained a mere wage earning means with no rituals and consciousness. The detoxing method used introduced the conscious connections with the help of weavers. The organic cotton yarn GOTS approved in itself had good energy compared to a regular farm cotton. The organic cotton detoxed showed positive results.

The natural dye process is a slow process which introduces good positive and therapeutic qualities in any yarn. The results of tests conducted from a regular cotton yarn dyed with natural dye showed positive results and it was enhanced when organic detoxed cotton yarn was dyed with natural dye made with detoxed waters which proved that conscious connective processes imbibe positive energies in the materials.

The $100 \%$ organic natural dyed handloom cotton horoscope fabric when compared with a colour wheel design in the same composition showed greater positive energies.

The detoxification processes proved that slowing down in all the processes of supply chain in textiles and apparel making imbibes positive energies in the hand made products. This research also introduced the age old practices of following rituals and conscious connections around weaving processes and proved that horoscope weaving which is the signature fabric of each of the subject had more positive energy. This reinstates that customized clothing (like in olden days of the kings) does have an impact on the energy fields of the material which will in turn enhance the energy fields of the person wearing the clothing.

The gas discharge visualization machine which measures the energy field in humans showed significant and positive results pre and post $100 \%$ organic natural dyed handloom cotton horoscope fabric.

All the forty subjects were tested pre and post organic clothing. The energy fields were tested for right projection area. The total (right, left and front) projection area increased in $87 \%$ of the subjects. The reading with filter which records the physical attributes and without filter which records the psycho emotional attributes showed significant positive increase in energy fields due to $100 \%$ organic natural dyed handloom cotton horoscope fabric.

\section{Acknowledgements}

First and foremost I would like to thank Former Dean, College of Home science, emeritus professor (ICAR) and my PhD advisor Dr. A. Sharada Devi, for supporting me during these past four years.

I wish to thank Dr. C. Devakumar, ADG (Education Planning Development), ICAR for seeing this as an innovative research, believing in the possibilities of this research and visioning what can come forth from this. I am in deep gratitude for having received a sustainable grant through the development funds of the ICAR. I thank all the weavers, subjects and hundreds of my former students who with their creative work have inspired me immensely all my life. And to all those who believed and not believed in this research as each contribution gave me a perspective and made this work that much better.

\section{References}

[1] Attrill, M.J., Gresty, K.A., Hill, R.A., and Barton, R.A. (2008). Red shirt colour is associated with long-term team success in English football. Journal of Sports Sciences, 26: 577-582.

[2] Bechtold, T., A. Turcanu, E. Ganglberger and S. Geissler. 2003. Natural dyes in modern textile dyehouses - How to combine experiences of two centuries to meet the demands of the future? Journal of Cleaner Production. 11(5): 499-509.

[3] Carruthers Helen, Julie Morris, Nicholas Tarrier and Peter Whorwell, J. 2010. The Manchester Color Wheel: development of a novel way of identifying color choice and its validation in healthy, anxious and depressed individuals. BMC Medical Research Methodology. 10:12

[4] Sharron Lennon, J and Leslie Burns, D.2000. Diversity of Research in Textiles, Clothing, and Human Behavior: The Relationship between What We Know and How We Know. Clothing and Textiles Research Journal. September 2000. 18 (4) $213-226$ 
[5] Udai Pratap Singh, Narendra Nath Singh \& Rai, K K. (2011). The Effect of Magnetically Restructured Water on Mustard (Brassica juncea) Crop and its Aphids. http://www.iet-community.org/iwone/IWONE5/abstracts.html

[6] Edward Witten. 1981. A New Proof of the Positive Energy Theorem. Communication in Mathematical Physics. 80(3): 381-402

[7] Carl Honoré. 2004. In Praise of Slowness: How A Worldwide Movement Is challenging the cult of Speed, Orion Books, London

[8] Charu Jain. 2005. The Conventional verses Bio processing of Organic and Conventional Cotton Fibers, Proceedings of the International Textile Conference, Chennai, India.

[9] Farthing G (1992). The Psychology of Consciousness. Prentice Hall. New York, USA

[10] ITEM. 2007. Polycontrast interference photography (PIP): Energy Field Video Imaging System, Getting Started Handbook, Innovation Technologies and Energy Medicine.

[11] Konstantin Korotkov. 2012. The Energy of Consciouness. BioInternet Series. http://www.gdvplanet.com/component/k2/item/120the-energy-of-consciousness

[12] Martinez Hewlett. 2012. The Case for Subtle Human Energy: Diagnostic and Therapeutic Approaches. Department of Molecular and Cellular Biology and Program in Integrative Medicine

[13] Bonnie Tarses. Horoscope Weaving. Oct 2010. www.bonnietarses.com/horoscopeweaving 